\title{
Improvement on Gross Motor Skills of Intellectual Disability Students through Games
}

\author{
Ali Priyono ${ }^{1, *}$, Udi Sahudi ${ }^{1}$, Yudy Hendrayana ${ }^{2}$ \\ ${ }^{1}$ Physical Education Study Program, Universitas Majalengka, Majalengka, Indonesia \\ ${ }^{2}$ Faculty of Sport and Health Education, Universitas Pendidikan Indonesia, Bandung, Indonesia
}

Received April 24, 2021; Revised June 15, 2021; Accepted July 21, 2021

\begin{abstract}
Cite This Paper in the following Citation Styles
(a): [1] Ali Priyono, Udi Sahudi, Yudy Hendrayana, "Improvement on Gross Motor Skills of Intellectual Disability Students through Games," International Journal of Human Movement and Sports Sciences, Vol. 9, No. 4A, pp. 20 - 24, 2021. DOI: 10.13189/saj.2021.091304.
\end{abstract}

(b): Ali Priyono, Udi Sahudi, Yudy Hendrayana (2021). Improvement on Gross Motor Skills of Intellectual Disability Students through Games. International Journal of Human Movement and Sports Sciences, 9(4A), 20 - 24. DOI: 10.13189/saj.2021.091304.

Copyright $\odot 2021$ by authors, all rights reserved. Authors agree that this article remains permanently open access under the terms of the Creative Commons Attribution License 4.0 International License

\begin{abstract}
People with Intellectual Disability (ID) can and do learn new skills, but they learn them more slowly. Children and adults who were consistently retarded were found to be significantly lower than non-retarded people in measures of physical development, gross motor skills, and fine motor skills. The purpose of this study was to determine the effect of games toward gross motor skills on ID students. This study uses a quantitative method with a quasi-experimental design. Subjects were 28 moderate mental retardation students institutionalized at the Gelora Karya Special Needs School Majalengka, West Java, Indonesia. The Sig value obtained was 0.001 and the $\mathrm{T}$-score was 3.774 . The value of 0.025 is a significant level obtained from 0.05: $2=0.025$ and 20 is the degree of freedom (df), namely $n-k-1=22-1-1=20$. These results indicate that games have an influence on students' motor skills. Games can develop themselves optimally in physical, motor, social, emotional and cognitive aspects. Moderate mentally retarded students have difficulty doing physical activities or basic movements. They can participate in playing activities but with simple directions, therefore they need practices that can develop their physical motor skills.
\end{abstract}

Keywords Gross Motor Skills, Intellectual Disability, Mentally Retarded, Games, Physical Education

\section{Introduction}

Children with special needs are children who have abnormalities or deviations from the average condition of normal children physically, intellectually, socially and emotionally. Researchers focus on children with mental retardation special needs. A child with mental retardation is a child who actually experiences obstacles and mental developmental retardation far below average (IQ below 70). They experience difficulties in academic, communication and social tasks, and carry out running. This obstacle occurs before the age of 18 years. At this age, the speed of thinking and the accuracy of movement is different from the general student.

Intellectual Disability (ID), known as mental retardation, is an intelligence with below average mental abilities and skills necessary for everyday life. People with ID can and do learn skills, but they learn more slowly. The term ID is used in this paper. Besides, various terms had also been used, including mental retardation and learning disabilities. In a study, motor speed and accuracy of ID children were related to cognitive speed and accuracy. It is suggested that the possibility that a motor-cognitive control link exists in children with ID [1]. Interpretation of literature in motor characteristics of retarded persons is made particularly difficult by the plethora of overlapping terms and concepts used to describe motor proficiency and development. Frequently, terms like motor skill, motor ability, motor proficiency and motor development are used interchangeably in published reports [2]. ID is a condition that is characterized by the impairment of global mental abilities and the consequent limitations in the individual's adaptive 
functioning. The latter is broadly based on the person's ability to perform day-to-day activities and involves three main skills: the ability to conceptualize, the ability to socialize, and the ability to perform practical tasks [3].

Fundamental movement skills (FMS) constitute an important set of skills that are believed to form the essential prerequisite foundations of more complex movements that are often required in different forms of physical activity [4]. Learning fundamental gross motor skills is a vital part of every young child's developmental process [5]. Early childhood is an ideal stage to introduce fundamental gross motor skills they will use throughout life. Head Start curriculums are designed to meet the needs and to maximize the strengths of each child [4]. Gross motor skills development, however, seems to support the literature reviewed. Gross motor skills can be influenced by appropriate movement programs so it is advisable to program gross motor skills at another level [6]. The researchers are interested in making a program on moderate mentality retarded. Motor is all body movements, including internal motion that is not observed (motor), namely the capture of stimuli by the senses of delivering stimuli by sensory nervous systems to the brain (memory) processing and decision making by the brain, delivering decisions by the nervous system, motor muscles, and observable external motion.

Motor movements include locomotor motion, non-locomotor motion and manipulative motion. Motor skills in early childhood are necessary to develop children's intelligence in the fields of language development, cognitive, art and creativity. Physical education taught in schools has a very important role, which is to provide opportunities for students to be directly involved in various learning experiences through physical activities. Competency standards and basic competencies for mentally retarded students are adjusted to the conditions of children with special needs. Motor skill development influences the entirety of a child's growth. Numerous studies have reported that fundamental motor skill acquisition is clearly associated with the development of neuromotor, cognitive, social, and emotional skills in childhood [7].

Games are physical activities carried out by individuals or groups with the aim of getting the pleasure generated in these activities. Playing is any activity for pleasure, and thus, games can also develop the skills and abilities of students with special needs or children with disabilities. In this study, treatment was given in the form of games based on motor learning for several weeks. Subjects with mental retardation who studied too many motor learning tasks maintained significant task retention after four weeks without reinforcement. Subjects with mental retardation who learned too many motor learning tasks were superior in retention after four weeks of no reinforcement for subjects who studied but did not learn too much [8]. Playing exercises can improve motor development in mentally retarded students [9]. When the play is adapted to the child's capabilities and characteristics (as it is adapted to the children with ID), the child is able to use his abilities according to the play type, and in this way the child can show his dormant abilities. If he/she lacks an ability, he/she may become acquainted with the ability and develop that ability. Therefore, as the play expands most of the developmental aspects, adaptation play and play style can affect these abilities, including improvement of motor skills. In addition to this, as the adapted play occurs in the group, it will encourage the child to enter the group and imitate the play skills from other children and learn about the correct movement and motor skills. The results of this imitation are creation and development of child's motor activities.

A previous review of the role of sport, physical education, and physical activity in children social inclusion identified four influential activities, including reducing social and economic distance, increasing feelings of belonging and acceptance, providing opportunities to increase knowledge and skills, and personal empowerment [10]. Basic knowledge of the course of motor development and the development of movement-oriented interventions are needed to reduce inactivity in the daily life and care of people with ID. Overall, based on the current, it can be concluded that motor activation of ID sufferers is somewhat limited [11]. Participation in sports can support the development of teamwork skills and connections with community members for people with and without disabilities [12]. In other words, physical education is concerned with learning the skills and understanding required for participation in physical activities, knowledge of one's own body and its range of and capacity for movement; and it is also a context for and means of learning a wide range of outcomes which are not inherent to physical activity, but which are valuable extrinsic educational lessons, such as social skills, aesthetic judgement, literacy and numeracy [10]. Individuals with ID may be at greater risk for diseases associated with a sedentary lifestyle. It is important that processes are put in place to facilitate physical activity opportunities for all persons with ID. Even doing physical activity at a later date can help with positive health outcomes [13]. PsyMot is a psychomotor therapy consisting of a series of games and reflective interviews that, in combination, assess mental and bodily functions. Psychomotor therapy uses body awareness exercises and physical activity as therapeutic tools to stimulate reflection and improve mental health [14]. Physical activity has a positive impact on ID, but further research is needed that examines various physical activities on ID [15]. Interesting and attractive sports games and integrated sports programs were highly recommended. The difficulty levels of the training task should increase relatively slowly and gradually based on the characteristics of children with ID [16]. Several studies have been conducted on the role of physical activity in persons with 
intellectual disabilities. However, little research has been done on the contribution of physical activity in the form of play and gross motor skill development to physical fitness in ID students and no research has examined the need to better understand how involvement in sustained and deliberate involvement in physical activity or sport can encourage participation and inclusion through sports games that are more meaningful for people with ID. For this reason, this study was aimed to determine the effect of learning game-based physical activity on improving gross motor skills of ID students.

\section{Methods}

The study used quasi experimental design research with one-group pretest-posttest design. The population in this study were all students with mental retardation with a total of 28 students. In this study, there were criteria for mentally retarded students, namely mild mental retardation, moderate mental retardation, and severe mental retardation. Therefore, researchers consider mentally retarded students with the criteria for mild mental retardation. This study uses a purposive sampling technique where the researcher determines the sample based on certain criteria. In this study, the samples were students who had light criteria. Twenty eight children with mentally retarded in Dawuan's Gelora Special School, Majalengka Regency, West Java Province, Indonesia were selected as the sample.

The instrument used in this study was the Motor Ability Test. This test consists of several forms of test. Motor ability tests include agility test, coordination test, balance test, and speed test. The agility test used the $4 \times 10$ meter shuttle run test, the coordination test used the catch ball test against the wall, the balance test used the positional balance stork stand test, and the speed test used the 30-meter sprint test. The motor ability test can improve locomotor motion, non-locomotor motion and manipulative motion.

This research design is made for researchers to answer research problem questions validly, objectively, precisely, and efficiently. This study uses quasi experimental design research which aims to obtain information which is an estimate for the information that can be obtained by the actual experiment in a situation where it is not possible to control and manipulate all relevant variables. This study, researchers used a one-group pretest-posttest design, which aims to determine the effect of a treatment. The treatment given in this study was motor learning in the form of small ball games on the ability to move students with mental retardation. This research has received approval from various parties such as students, schools used as research locations, and parents of students. This research was conducted for 6 weeks.

The data analysis and processing techniques in this study used the Paired Sample t-test by first using the normality and homogeneity test to determine whether the sample was taken from a population that is normally distributed and homogeneous or not.

Table 1. Motor ability test

\begin{tabular}{cccc}
\hline Item test & Mean & Min Score & Max Score \\
\hline Shuttle run & 14.81 & 20.65 & 10,35 \\
Coordination test & 11,63 & 3 & 24 \\
Stork stand positional & 11.29 & 2.96 & 30.44 \\
balance test & & & \\
Sprint & 7.50 & 13.05 & 5.16 \\
\hline
\end{tabular}

\section{Results}

From the results of data processing, the average value is obtained and the basis for testing normality is provided that if the significant value is $>0.05$, then the value is normally distributed and if the significant value is $<0.05$, then the value is not normally distributed. It is known that, in the normality test presented in Table 2, the pretest and posttest data are above a significant value $>0.05$, so it can be concluded that the pretest and posttest data above are normally distributed. Meanwhile, in the homogeneity test, researchers used One Way ANOVA. The basis for testing this homogeneity is provided that if the significant value is $>0.05$, it is said that the value is Homogeneous and if the significant value is $<0.05$, then it is said that the value is not homogeneous. It is known that the pretest and posttest significant value is greater than the significant value $>0.05$, so it can be concluded that the pretest and posttest data above have homogeneous data. The data are presented in Table 3.

Table 2. Pretest and posttest normality test

\begin{tabular}{c|ccc}
\hline \multirow{4}{*}{ Normality test } \\
\hline \multirow{3}{*}{ Pretest } & \multicolumn{3}{|c}{ Shapiro-wilk } \\
\cline { 2 - 4 } Posttest & Statistics & df & sig. \\
\cline { 2 - 4 } & 0.965 & 22 & 0.598 \\
& 0.965 & 22 & 0.607 \\
\hline
\end{tabular}

Table 3. Homogeneity results of pretest and posttest

\begin{tabular}{cccc}
\hline Results & Levine Statistic & Sig. & \\
\hline $\begin{array}{c}\text { Pretest and } \\
\text { Posttest }\end{array}$ & 0.207 & 0.651 & Homogeneity \\
\hline
\end{tabular}

Based on the results of data processing, researchers tested the hypothesis using the Sample paired t-Test. This analysis is used to determine the effect of play on gross motor skills in ID. Table 4 shows that the decision is based on the probability value and the T-count value with the T-table, namely if the Sig. less than $(<) 0.05$ or T-count more than (>) T-table. So, it can be concluded that gross motor skills through games have an effect on mild mental retardation students. 
Table 4. Research hypothesis testing results

\begin{tabular}{cccc}
\hline Group & T Score & T Table & Sig. \\
\hline Experiment & 3.774 & 2.086 & 0.001 \\
\hline
\end{tabular}

\section{Discussions}

Children with disabilities have the same rights to get a learning service, especially about physical education learning. The purpose of testing disability studies and specifically disability studies in education is to overcome disability policy issues such as the right to education, work life and lifelong learning [17]. The aim is to test learning, especially disability learning in education to address disability policy issues such as the right to education, working life and lifelong learning. Physical educators can design modifications and accommodation to suit students' needs by differentiating their learning and broadening their learning. The result showed that learning goals should be achievable for students with various abilities. The environment can also change to support inclusion, either by adjusting boundaries, aligning equipment height and distance, or making sure to use brightly colored and equipped with target audio [18].

Educators must design a lesson by modifying and accommodating to suit the needs of students by differentiating their lessons and expanding their learning. The result showed that learning objectives should be achievable for students with various abilities. The environment can also change to support inclusion, either by adjusting boundaries, aligning equipment height and distance, or making sure to use brightly colored and targeted audiences. It can be concluded that disability studies in education are to address disability policy problems such as the right to education, and educators must have a way to provide material by modifying learning properly so that it could ensure that the target is achievable.

Small ball games are games that use small ball media in small ball games. Several motor aspects, such as locomotor, non-locomotor, and manipulative motions are involved. By playing small ball games, mentally retarded students, who have difficulty doing or improving motion and following educational learning physical education, look enthusiastic and have a high desire to move and take part in physical education learning. Actually, children do not need to be told or stimulated to move, because automatically the children will be happy to make movements. That's when we as educators pay attention to how basic locomotor, non-locomotor and manipulative movements develop optimally [19]. Learning children with mild ID must be carried out with simple instructions and accompanied by direct and concrete demonstrations to make it easier for children with ID to accept because children with ID are slower in cognitive development, and their mental operations might be confined to concrete objects and events. Verbal instructions with examples of the correct movements will be easier to imitate by children with ID, therefore the teacher places more emphasis on practicing the movements that the child must do [20].

Understanding individuals with learning disabilities is very important to show empathy and see paint from their perspective, often individuals with learning disabilities need help to feel empowered [19]. Understanding individuals with active learning is essential to show empathy and see pain from their point of view, often individuals with learning disabilities need help feeling empowered.

The importance of external settings in determining one's ability set. He proposes a combined ability that results from complex interactions between one's internal abilities [fluids, dynamic characteristics of people] and external conditions that allow for the opportunities they have of choices and actions in specific political, social and economic situations [20]. Games can improve the gross motor skills of mentally retarded students and playing has benefits that can be felt directly by students in addition to creating a sense of pleasure to play, it can also develop themselves optimally both in physical, motor, social, emotional and cognitive aspects.

Motor ability or often called motor movement ability is an ability that a person has from birth. Motor ability is the immediate condition of a person to display various variations of movement skills, especially in sports activities. There are four abilities that are directly related to sports skills, namely coordination, kinesthetic, balance and speed of movement. The facilities used must support learning as According "That special education facilities can mainstream education through the identification and assessment of students with disabilities and the administration of the most important training and resources for teaching staff in public schools [21]. Those special education facilities can prioritize education through the identification and assessment of students with disabilities and the administration of training as well as resources for teachers in public schools.

\section{Conclusion}

The conclusion of this study can be seen from a hypothesis test, so it can be concluded that the student participation in physical activities through sports games has a positive impact on improving health, social skills, and gross motor skills of ID students.

\section{Acknowledgement}

The authors are very grateful to all of the students involved in the study, as without them this project could not have been achieved. 


\section{REFERENCES}

[1] Hirata S, Okuzumi H, Kitajima Y, Hosobuchi T, Kokubun M. Speed and accuracy of motor and cognitive control in children with intellectual disabilities. Int J Dev Disabil. 2013;59(3):166-78.

[2] Bruininks RH. Physical and Motor Development of Retarded Persons. Int Rev Res Ment Retard. 1974;7(C):209-61.

[3] American Association of Intellectual and Developmental Disabilities. Definition of intellectual disability [Internet]. 2016. Available from: http://aaidd.org/intellectual-disabilit y/definition\#.V5zkcvkrK01

[4] Woodard RJ, Yun J. The performance of fundamental gross motor skills by children enrolled in head start. Early Child Dev Care. 2001; 169(1):57-67.

[5] Capio CM, Eguia KF, Simons J. Test of gross motor development-2 for Filipino children with intellectual disability: Validity and reliability. J Sports Sci. 2016; 34(1):10-7.

[6] Wang JHT. A study on gross motor skills of preschool children. J Res Child Educ. 2004;19(1):32-43.

[7] Battaglia G, Alesi M, Tabacchi G, Palma A, Bellafiore M. The development of motor and pre-literacy skills by a physical education program in preschool children: A non-randomized pilot trial. Front Psychol. 2019; 9(JAN):110 .

[8] Chasey WC. Overlearning as a variable in the retention of gross motor skills by the mentally retarded. Res Q Am Assoc Heal Phys Educ Recreat. 1971;42(2):145-9.

[9] Malekpour M, Isfahani AS, Amiri S, Faramarzi S, Heidari T, Shahidi MA. The effect of adapted play training on motor development of students with intellectual disabilities. Br J Dev Disabil. 2012;58(2):120-7.

[10] Bailey R. Evaluating the relationship between physical education, sport and social inclusion. Educ Rev. 2005;57(1):71-90.

[11] van der Putten AAJ, Bossink LWM, Frans N, Houwen S, Vlaskamp C. Motor activation in people with profound intellectual and multiple disabilities in daily practice. J Intellect Dev Disabil. 2017;42(1):1-11.

[12] Thomson A, Bridges S, Corrins B, Pham J, White C, Buchanan A. The impact of physical activity and sport programs on community participation for people with intellectual disability: A systematic review. J Intellect Dev Disabil [Internet]. 2020;0(0):1-11. Available from: https://doi.org/10.3109/13668250.2020.1717070

[13] Temple VA, Walkley JW. Physical activity of adults with intellectual disability. J Intellect Dev Disabil. 2003;28(4):342-53.

[14] Kay JJ, Clegg JA, Emck C, Standen PJ. The feasibility of psychomotor therapy in acute mental health services for adults with intellectual disability. J Intellect Dev Disabil. 2016;41(1):54-60.

[15] Temple VA, Walkley JW. Perspectives of constraining and enabling factors for health-promoting physical activity by adults with intellectual disability. J Intellect Dev Disabil. 2007;32(1):28-38.

[16] Ma Y, Wang L, Li M, Wang T. Meta-analysis of the effects of exercise programs in improving the balance ability of children with intellectual disabilities. J Intellect Dev Disabil [Internet]. 2020;45(2):144-54. Available from: https://doi.org/10.3109/13668250.2019.1632040

[17] Hakala K, Björnsdóttir K, Lappalainen S, Jóhannesson IÁ Teittinen A. Nordic perspectives on disability studies in education: a review of research in Finland and Iceland. Educ Inq [Internet]. 2018;9(1):78-96. Available from: https://doi.org/10.1080/20004508.2017.1421390

[18] Eccles JS, Barber BL, Stone MR, Hunt JE. Extracurricular activities and adolescent development. J Soc Issues. 2003;59(4):865-89.

[19] Siregar, N. M., Sari, E. F. N., Budiningsih, M., \& Zulham. The basic learning model of traditional motion based games for early childhood (5-6) years. Int J Hum Mov Sport Sci, 9(1), 81-88, 2021. DOI: 10.13189/saj.2021.090111

[20] Kesumawati, S. A., Fakhruddin, \& Fahritsani, H. Learning model of fundamental movement skills (FMS) for children with mild intellectual disability. Int J Hum Mov Sport Sci, 9(1), 71-80, 2021. DOI: 10.13189/saj.2021.090110

[21] Maestri-Banks A. Learning Disability, Education and Empowerment: Learning from Individuals who live with a Learning Disability. Heal Soc Care Educ. 2013;2(1):21-4.

[22] Lim S. The Capabilities Approach to Inclusive Education: re-envisioning the Individuals with Disabilities Education Act's Least Restrictive Environment. Disabil Soc [Internet]. 2020; 35(4):570-88. Available from: https://doi.org/10.1080/09687599.2019.1649119

[23] Tones M, Pillay H, Carrington S, Chandra S, Duke J, Joseph RM. Supporting Disability Education through a Combination of Special Schools and Disability-Inclusive Schools in the Pacific Islands. Int J Disabil Dev Educ [Internet]. 2017; 64(5):497-513. Available from: http://dx.doi.org/10.1080/1034912X.2017.1291919 